\title{
Essential gains and health after upper-limb tetraplegia surgery identified by the International classification of functioning, disability and health (ICF)
}

\author{
L Bunketorp-Käll ${ }^{1,2,3}$, C Reinholdt ${ }^{1,3}$, J Fridén ${ }^{1,3,4}$ and J Wangdell ${ }^{1,3}$
}

Study Design: A questionnaire-based survey.

Objectives: To describe functional gains and health following upper-limb tetraplegia surgery using the International Classification of Functioning, Disability and Health (ICF) as a reference and to explore interconnections across different dimensions of functioning and health.

Setting: A specialized center for advanced reconstruction of extremities at Sahlgrenska University Hospital, Gothenburg, Sweden. Methods: Fifty-seven individuals who participated in a satisfaction survey were included in the present study. Besides questions concerned with the respondents' satisfaction with different aspects of surgery, the measures included perceived overall health status (EQ-VAS) and achieved grip strength. Univariate analyses were used to explore interconnections between measures.

Results: The gains could be subcategorized and linked to the ICF domains 'mobility', 'self-care', 'communication', 'domestic life', and 'community, social and civic life', with 'handling objects' and 'maneuvering a wheelchair' as the most frequently reported gains. The mean EQ-VAS score was $67 \pm 22$. No significant correlation was shown between grip strength and activity gains, nor between grip strength and perceived overall health. The degree of satisfaction was, however, associated with self-reported overall health among participants.

Conclusion: The functional gains achieved after tetraplegia surgery could be applied to the ICF constructs' body functions/structures and activity with possible implications on participation. The overall health perception was relatively high and could be linked to the degree of satisfaction among participants. Muscle strength is not necessarily transferable to activity performance. This emphasizes the importance of addressing factors other than strength in the post-surgical rehabilitation and assessments.

Spinal Cord (2017) 55, 857-863; doi:10.1038/sc.2017.36; published online 18 April 2017

\section{INTRODUCTION}

Loss of independence is the greatest challenge a person with tetraplegia faces. Reconstruction of upper-limb motor functions involves a number of surgical interventions focusing on restoring elbow extension and grip functions that can help improve the degree of independence in patients. The combinations of surgical procedures provide more options for improved function in this population than ever before. ${ }^{1,2}$ Assessment of outcome is an essential part of tetraplegic upper-limb surgery. ${ }^{3}$ However, the great variety of neurological deficits and differing surgical and functional goals make outcome assessment a challenge. ${ }^{4}$ Evaluations are usually performed objectively using physical parameters such as grip strength and range of movement. Satisfaction may, however, be one of the most desired outcomes and even an element of the actual health status, ${ }^{5}$ contributing to a global evaluation of surgical and rehabilitation outcomes.

The data from satisfaction surveys can be linked to the International Classification of Functioning, Disability and Health (ICF), ${ }^{6}$ providing a conceptual framework for the discussion of the clinical relevance of outcomes experienced by tetraplegia patients. ${ }^{7,8}$ Integration of the ICF model is recommended in the management of patients with $\mathrm{SCI},{ }^{7-9}$ to aid the interpretation of hand function outcomes following tendon transfer surgery for individuals with tetraplegia.7,8 The conceptual framework (Figure 1) describes the interactive process of an individual's journey toward meaningful life participation after the onset of a challenging health condition. ${ }^{6}$ The ICF framework consists of two parts, each with two separate components. Part 1 covers function and disability, and includes the following components: (1) body functions and structure (describing actual anatomy and physiology as well as psychology of the individuals) and (2) activities and participation (describing the person's functional status, including learning and applying knowledge, general tasks and demands, communication, mobility, self-care, domestic life, interpersonal interactions and relationships, major life domains and community, social and civic life). Part 2 covers contextual factors and includes the following components: (1) environmental factors (factors that are beyond an individual's control, such as family, work, government

${ }^{1}$ Department of Orthopaedics, Center for Advanced Reconstruction of Extremities (C.A.R.E.), Sahlgrenska University Hospital, Mölndal, Sweden; ${ }^{2}$ Department of Clinical Neuroscience, Institute for Neuroscience and Physiology, Sahlgrenska Academy, University of Gothenburg, Gothenburg, Sweden; ${ }^{3}$ Department of Orthopaedics, Institute of Clinical Sciences, Sahlgrenska Academy, University of Gothenburg, Gothenburg, Sweden and ${ }^{4}$ Swiss Paraplegic Centre, Nottwil, Switzerland

Correspondence: Dr L Bunketorp-Käll, Department of Orthopaedics, Center for Advanced Reconstruction of Extremities (C.A.R.E.) Sahlgrenska University Hospital/Mölndal, House U1, 6th floor, 43180 Mölndal, Sweden.

E-mail: lina.bunketorp-kall@neuro.gu.se

Received 17 October 2016; revised 3 March 2017; accepted 12 March 2017; published online 18 April 2017 


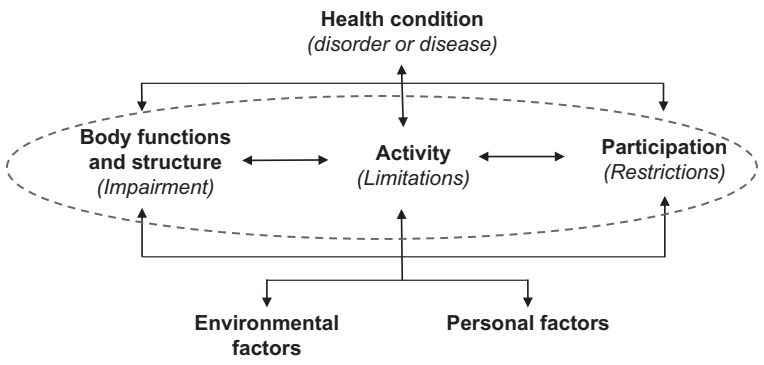

Figure 1 Interactions of the different components in the International Classification of Functioning, Disability and Health (ICF) model. A full color version of this figure is available at the Spinal Cord journal online.

agencies, laws and cultural beliefs) and (2) personal factors (including race, gender, age, educational level, coping styles and so on). ${ }^{6}$ The framework relates to impairments in body functions and organ systems in relation to activity restrictions. It also relates to how those restrictions influence a person's ability to participate in everyday life. ${ }^{6}$ In order to facilitate implementation of the ICF in clinical practice and research, concise and comprehensive ICF Core Sets have been developed for most of the common chronic conditions, including individuals with spinal cord injury (SCI) in both the early post-acute and the long-term context. ${ }^{10,11}$

The effects of tetraplegia surgery and rehabilitation on performance and satisfaction of patient activity goals have previously been identified in 20 of our patients 6 and 12 months following surgical grip reconstruction, restoration of thumb and finger flexion and opening of the hand. The Canadian Occupational Performance Measure (COPM) was used before and after the surgery, and the results were linked to the ICF concept. ${ }^{12}$ The study demonstrated that both selfrated performance and satisfaction with individually prioritized goals improved at 6 months, and in some individuals continued to improve at 12 months. The surgical intervention was shown to impact on all domains of the ICF model such as improved upper-limb performance and balance, as well as independence and control in everyday life. ${ }^{13}$ Significant improvements in the basic activity of eating and more complex activities such as doing housework and taking part in leisure activities were reported. ${ }^{14}$ The results of surgical reconstructions in 57 tetraplegic patients treated between 1982 and 1990 were reviewed in a study by Mohammed et al. ${ }^{15}$ The study demonstrated predominantly favorable long-term functional outcomes, particularly in terms of participation for a minimum of 12 years and up to 18 years following surgery. A 10-year review of hand function outcome for 24 tetraplegic individuals included in the cohort initially reported by Mohammed et al. in $1992,{ }^{15}$ who had received bilateral reconstructive surgery, was conducted. The study demonstrated that levels of functional independence, expectations and satisfaction had been maintained over time. ${ }^{16}$ In order to evaluate the effects of aging on hand function, including grip and pinch strength among patients with tetraplegia, a second follow-up study was conducted by Dunn et al. 11 years later ${ }^{17}$ on the same study cohort. The results suggest that key pinch and grip strength levels are maintained for many years following reconstructive surgery. The decrease in strength of those with active transfers over the 11-year period was reported to be within the expected age-related loss for the general population. ${ }^{17}$ However, because surgical techniques have improved greatly since then, a new assessment is needed. Moreover, as previously reported, the endpoint of recovery after tetraplegia upper-limb surgery is an issue, which remains largely unresolved. Functioning may continue to improve in the long-term, as motor control and improvements in the use of the hand appear to continue for some time after surgery.

In order to determine long-term satisfaction after reconstructive upper-limb tetraplegia surgery, a questionnaire-based survey in a Swedish study cohort has previously been conducted. ${ }^{18}$ The average time elapsed since surgery was 6 years (range $=1-11$ ). The participants' responses to the questions in the following three categories: satisfaction, activities and employment/education were positive in 83,72 and $31 \%$, respectively. Ninety-five percent responded that the surgery had been beneficial, which is similar, albeit slightly higher as compared with previous studies conducted in the United States, the Netherlands and Denmark, where the proportion of positive responses ranged between 80 and $90 \% .{ }^{19-21}$ In the Swedish satisfaction survey, it was concluded that surgical interventions are rewarding from a patient perspective, because they lead to improvements in daily life as well as enhanced quality of life. ${ }^{18}$ None of the previous satisfaction surveys conducted in the United States, the Netherlands and Denmark have used the ICF to interpret the results. ${ }^{19-21}$

The choice of surgical procedures depends on the available donor muscle strength according to the Medial Research Council grading system and the International Classification of Surgery of the Hand in Tetraplegia., ${ }^{1,22}$ The strength of the available donor muscles is considered to be an important determinant of the success of tetraplegia upper-limb surgery. Donor muscles must be healthy, of adequate strength (achieving at least M4 out of a maximum grade of M5), preferably neither injured nor reinnervated. However, if available donors are limited, weaker muscles (M3) may be used. ${ }^{1}$ After hand trauma, a correlation has been demonstrated between recovery of grip strength, gains in overall hand function and daily living activity improvements. ${ }^{23}$ It is suggested that grip strength measures should be used along with functional measures to appropriately assess overall hand function following hand trauma. ${ }^{23}$ A previous study investigating the relationship between body functions and activity improvements after tetraplegia surgery showed that, 1 year after surgery, there was no correlation with any of the physical parameters, including grip strength. ${ }^{24}$ We could find no studies that have tested for an association between grip strength and long-term overall satisfaction after tetraplegia surgery.

How individuals with tetraplegia view their health status following upper-limb reconstructive surgery is also of great interest. Although previous studies clearly demonstrate that the degree of satisfaction after tetraplegia surgery is high, for some individuals, the perceived overall health may not be satisfactory. We could find that no studies aimed at determining the perception of overall health following tetraplegia surgery. It is not known whether there is any correlation between the degree of satisfaction and participants' perceived overall health status. Emphasis should therefore be placed on exploring the association between physical parameters and individuals' overall health.

\section{Objectives}

The aim of this study was to describe patient-reported long-term gains and overall health status following upper-limb tetraplegia surgery using the ICF. An additional aim was to explore the interconnections across measures of the different dimensions of participants' functioning and health. More specifically, the aim was to investigate whether there is a correlation between achieved strength in restored grip functions at 6 and 12 months after surgery, perceived long-term satisfaction and overall health status among participants. 


\section{MATERIALS AND METHODS}

Study design and participants

A questionnaire-based survey was previously designed to assess long-term satisfaction and self-rated health following reconstructive upper-limb surgery in individuals with tetraplegia. The setting was at The Sahlgrenska University Hospital, Gothenburg, a community hospital in southwest Sweden, which offers reconstructive upper-limb surgery to individuals with tetraplegia. A total of 57 individuals with tetraplegia who underwent upper-limb reconstructive surgery between the years 2005 and 2014 took part in the study. A detailed description of the results of the satisfaction survey has been reported previously. ${ }^{18}$

\section{Measures}

A modified and translated version of the questionnaire developed by Wuolle et al. ${ }^{19}$ was used in the study. As in the original version of the questionnaire, participants are asked to respond to several statements on a five-point Likert scale ranging from 1 to 5 (strongly disagree, disagree, neutral, agree and strongly agree). The first part of the questionnaire was divided into the following categories: (1) satisfaction (9 statements) (2) activities (5 statements) and (3) employment/education ( 5 statements) based on findings in the study by Fock-Feenstra et al. ${ }^{20}$ Part 2 consists of one question regarding the appearance of the hand after surgery, and two questions regarding changes in the functional ability of participants after triceps- and hand/wrist surgery, respectively. Part 3 contains open questions where the respondent is asked to list activities in which their function was improved after surgery as well as to report whether the surgery has complicated certain tasks. Respondents are also asked to mention any other disadvantages with the surgery and to give general comments. The questionnaire is shown to be reliable both by test-retest analysis and by measurement of its internal consistency. ${ }^{18}$

Self-rated health was measured using the Visual Analogue Scale (VAS) included in the EuroQol five-dimension questionnaire-3L (EQ-5D-3L) that generates information concerning the respondents' perceived overall healthrelated quality of life. The respondent is asked to mark his/her health status on a $20 \mathrm{~cm}$ vertical scale with endpoints of 0 and 100, the endpoints being labeled 'the best health you can imagine' and 'the worst health you can imagine'. ${ }^{25}$

Functional characteristics were collected retrospectively from our database and from medical records. Since the main aim with grip reconstruction is the ability to close the hand and to grip objects, the measurement of grip strength in reconstructed grip functions was included. Physical parameters collected at the 6- and 12-month follow-up included palmar grip strength measured with Jamar hand dynamometer (North Coast Medical, Gilroy, USA), ${ }^{26}$ and key pinch strength measured with Preston Pinch Gauge (North Coast Medical, Gilroy, USA). ${ }^{27}$

\section{Data analysis}

The data analysis included the calculation of descriptive statistics. The mean and s.d. of the EQ-VAS ratings as well as the median and the first and third quartile were described. In order to explore the association between achieved grip strength at 6 and 12 months post surgery, long-term satisfaction and overall health status, univariate correlations were calculated using Spearman rank order correlation. This was also used to explore the association between satisfaction and the perception of overall health. A commonly used guideline for interpretation of ICC inter-rater agreement measures is as follows: Less than 0.40-Poor; between 0.40 and 0.59-Fair; between 0.60 and 0.74-Good; and between 0.75 and 1.00 -Excellent. ${ }^{28}$ Analyses were conducted using SPSS v.22.0 (IBM Corp., Armonk, NY, USA). All tests were two-sided and with $P<0.05$ as a level of significance.

\section{RESULTS}

The study cohort includes 15 women (26\%), with a mean age of 49 years (range: $24-77)$ and 42 men (74\%), with a mean age of 46 years (range: $23-78$ ) and is previously presented in detail. ${ }^{18}$ The mean age at the time of surgery was 41 years (range: 20-73), and the average number of years elapsed since the surgery was six (range: 2-11). The average number of years elapsed between the injury and the first surgery in the study cohort was six (range: 1-16).

\section{Use of the ICF conceptual framework to interpret satisfaction after} upper-limb tetraplegia surgery

The results from the satisfaction survey as a whole have previously been described in detail. ${ }^{18}$ The participants' answers to the open questions (part 3) were used in the present study, and were linked to the ICF model as recommended by Sinnott et al. ${ }^{7,8}$ In total, 49 participants $(86 \%)$ mentioned activities in which their function was improved after surgery. In Figure 2, satisfactory gains reported by

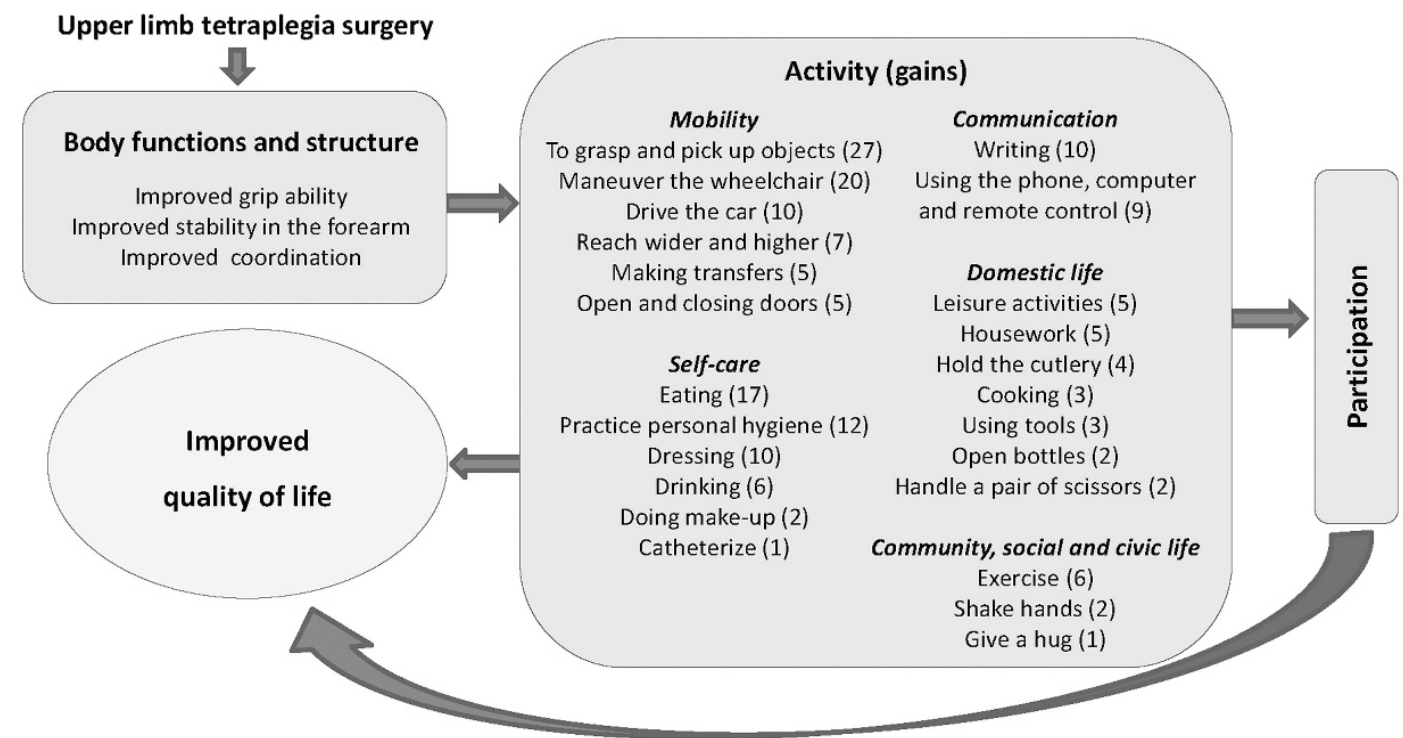

Figure 2 Satisfactory functional gains reported by 49 participants after upper-limb tetraplegia surgery divided into subgroups and their potential impact on participation. The functional gains are applied to the International Classification of Functioning, Disability and Health (ICF) constructs, body function/structures and activity. Arrows represent hypothesized directional links, and the number of participants reporting each activity is indicated in brackets. A full color version of this figure is available at the Spinal Cord journal online. 
the participants after upper-limb tetraplegia surgery are applied to the ICF constructs, body function/structures and activity. The most commonly reported subgroup of gains could be ascribed to the ICF category, mobility (Domain 4) with 'grasp and pick-up objects' and 'maneuver a wheelchair' as the two most frequent activity gains reported by $27(46 \%)$ and $20(41 \%)$ participants, respectively. 'Grasp and pick-up objects' could be applied to the ICF category, 'grasping (d4401)' and 'picking up' (d4400). The activities, 'driving a car' and 'making transfers' were also reported as being advantageous gains. The second most commonly reported subgroup of functional gains could be linked to the ICF category 'Self-care' (Domain 4), where 'eating', 'practicing personal hygiene' and 'dressing' were the most frequently reported activity gains. In the ICF category 'Communication', (Domain 3) the most commonly reported activity gains were 'writing' and 'using a communication device' such as a phone and a computer, as well as a remote control. The remaining functional gains reported by participants could be linked to the ICF category, 'Domestic life' (Domain 6) and 'Community, social and civic life' (Domain 9). The most frequently reported functional gains in these categories were 'leisure activities', 'housework' and 'exercise', respectively. Improvements in body function/structure undoubtedly enhance the participants' ability to perform activities, which in turn may impact on the degree of participation as well as personal and environmental aspects, as illustrated in Figure 2.

In Table 1 the gains reported by the participants are linked to the ICF classification system. All gains could be linked to categories within the Activity and Participation domain.
Self-reported health, satisfaction, grip strength and their intercorrelations

Fifty-four participants in the satisfaction survey (95\%) answered the question regarding perceived health as measured with EQ-VAS. The mean EQ-VAS score was $67 \pm 22$. The median EQ-VAS score was 70 , and the first and third quartile were 65 and 80, respectively. Records of strength in key pinch and cylinder grip were available for a subgroup of the participants and are presented in Table 2. Univariate analyses were employed to evaluate whether there was any association between achieved grip strength, reported gains as assessed by the satisfaction questionnaire and overall health status among participants. Intercorrelation matrix of the different dimensions of participants' functioning and health is presented in Table 3. Apart from a negative correlation between the category, general satisfaction and strength in the pinch grip at 12 months $(r=-0.43)$, no significant correlation was shown between grip strength in restored functions and gains with respect to the three satisfaction categories, 'general satisfaction', 'activity' and 'employment/education'. There was also no significant correlation between achieved grip strength and perceived health as measured with EQ-VAS. There was, however, a significant correlation between the degree of satisfaction with respect to all three categories, 'general satisfaction', 'activity' and employment/education', and respondents' self-reported overall health status (Table 3).

\section{DISCUSSION}

The present study demonstrates that patient-reported functional gains after tetraplegia surgery can be interpreted using the ICF constructs, body functions/structures and activity. The participants reported

\section{Table 1 Reported gains after upper-extremity surgery linked to the ICF classification system}

\begin{tabular}{|c|c|c|}
\hline \multirow[b]{2}{*}{ Gains } & \multicolumn{2}{|c|}{ ICF code and category titles } \\
\hline & Second level & Third level \\
\hline Writing & d170 (Writing) & \\
\hline $\begin{array}{l}\text { Using the phone, computer and remote } \\
\text { control }\end{array}$ & d360 (Using communication devices and techniques) & \\
\hline Grasp/pick-up objects & d440 (Fine hand use) & d4400 (Picking up) d4401 (Grasping) \\
\hline Using tools & $\begin{array}{l}\text { d440 (Fine hand use) and d650 (Caring for household } \\
\text { objects) }\end{array}$ & d4401 (Grasping) \\
\hline Handle a pair of scissors & d440 (Fine hand use) & d4401 (Grasping) \\
\hline Open and closing doors & d440 (Fine hand use) and d445 (Hand and arm use) & $\begin{array}{l}\text { d4401 (Grasping), d4403 (Releasing), d4450 (Pulling), } \\
\text { d4450 (Reaching) }\end{array}$ \\
\hline Reach wider and higher & d445 (Hand and arm use) & d4452 (Reaching) \\
\hline Give a hug & d445 (Hand and arm use) & d4452 (Reaching) \\
\hline Shake hands & d445 (Hand and arm use) & d4401 (Grasping), d4403 (Releasing) \\
\hline Open bottles & d550 (Eating) & \\
\hline Hold the cutlery & d550 (Eating) & \\
\hline Making transfers & d465 (Transferring oneself) & \\
\hline Maneuver the wheelchair & d465 (Moving around using equipment) & \\
\hline Drive the car & d475 (Driving) & \\
\hline Practice personal hygiene & d510 (Washing oneself) & \\
\hline Doing make-up & d520 (Caring for body parts) & \\
\hline Catheterize & d530 (Toileting) & d5300 (Regulating urination) \\
\hline Dressing & d540 (Dressing) & \\
\hline Eating & d550 (Eating) & \\
\hline Drinking & d560 (Drinking) & \\
\hline Cooking & d630 (Preparing meals) & \\
\hline Housework & d640 (Doing housework) & \\
\hline Leisure activities & d920 (Recreation and leisure) & \\
\hline Exercise & d920 (Recreation and leisure) & d9201 (Sports) \\
\hline
\end{tabular}


various activities in which they improved following surgery. The gains could be gathered into subcategories and linked to the domains 'mobility', 'self-care', 'communication', 'domestic life' and 'community, social and civic life'. The most frequently reported specific gain was 'to grasp or pick-up objects'. This particular activity gain could be linked very precisely to the ICF category, 'grasping (d4401)' and 'picking up' (d4400), included in domain 4 (Mobility). These results are in accordance with the findings of previous studies linking Upperlimb surgery to ICF domains. ${ }^{4,14,29}$ Clearly, patients' perception of satisfaction after upper-limb tetraplegia surgery is very high, ${ }^{18-21}$ and the gains could be linked to the ICF categories body functions/ structures and activity. The more active joints a person has, the better the ability to grasp, release and manipulate an object. ${ }^{30}$ Improvement in the ability to grasp and release objects enhances ADL performance, which in turn makes individuals more independent. ${ }^{8}$ ICF depicts participation as being influenced by impairments and activity limitations. ${ }^{6}$ Thus, improvements in the activity domain reported by the participants in the Swedish satisfaction survey are likely to have enhanced their level of participation.

The results of the Swedish satisfaction survey were linked to the ICF, as it provides a comprehensive framework and a common language for clinical practice and research. Although the ICF is neither an assessment nor a measurement tool, it does offer an opportunity for building a consensus on the terminology for describing disablement. It is thus a useful conceptual model that can be applied to, among other things, outcome measurement and research. ${ }^{6-11}$

Significant efforts have been made over the last few decades to better conceptualize and document rehabilitation outcomes and the quality of social participation of people with disabilities. ${ }^{31}$ Enhancing an individual's social participation is often recognized as one of the most important goals of the individual's rehabilitation process. ${ }^{31}$ Functional gains reported by participants in the present cohort such as the possibility to maneuver a wheelchair, drive a car, make transfers, pursue leisure activities and shake hands could be thought upon as having the potential to influence social participation. Using the phone and computer, shaking hands and giving a hug are other activities that could be categorized as social interactions. Efforts have also been made

Table 2 Achieved grip strength in restored grip functions (kg) 6 and 12 months following surgery

\begin{tabular}{ll}
\hline & Mean (s.d.) \\
\hline Key pinch at 6 months $(N=24)$ & $1.83(0.92)$ \\
Key pinch at 12 months $(N=25)$ & $2.20(0.94)$ \\
Cylinder grip at 6 months $(N=24)$ & $4.17(2.83)$ \\
Cylinder grip at 12 months $(N=19)$ & $5.04(2.44)$ \\
\hline
\end{tabular}

to reach consensus in outcome measures after upper-limb surgery in tetraplegia in order to cover many aspects of the outcome, using the ICF as a framework. ${ }^{4,14,17}$ Although the ICF conceptually distinguishes activities from participation in both its model of disability and its definitions, the ICF provides only one list of codes for activity and participation, leaving the user to decide whether all codes apply to both concepts or whether codes in some domains relate to activities, and codes in other domains reflect participation. ${ }^{32}$ Activity and participation are conceptually complex constructs. For this reason, whereas the ICF suggests that multiple methods should be used for classifying activity and participation, it has been suggested, as an alternative, that the combined ICF category encompassing activity and participation should be conceptualized and measured as two distinct constructs. ${ }^{33}$

The perception of overall health among participants in the present study was relatively high and could be linked to the degree of satisfaction among participants. In a previous Swedish study, Kreuter et al. compared the level of functioning, mood and global quality of life among patients with SCI and traumatic brain-injured (TBI) individuals with that of the general population. ${ }^{34}$ The perception of global quality of life (QL) was recorded on a visual analogue scale (VAS) and endpoints were labeled 'very low' and 'very high', similar to the EQ-VAS in the present study. Kreuter et al. showed that the mean VAS score in the SCI $(\mathrm{N}=167)$ and TBI population $(N=92)$ was $57.2 \pm 28$ and $63.5 \pm 24$, respectively. The mean VAS score in the general population $(N=264)$ was $69.8 \pm 21 .^{34}$ These findings suggest that, following reconstructive surgery, individuals with tetraplegia perceive their health status $10 \%$ higher as compared with a mixed SCI population $(67 \pm 22$ vs $57.2 \pm 28)$ (tetraplegia and paraplegia individuals), and slightly lower as compared with the group representing the general population, as reported in the study by Kreuter et al. ${ }^{34}$ It is thus reasonable to compare the results from this study with the study by Keuter et al., since both studies were carried out in the same geographic area. The global measure EQ-VAS has, to our knowledge, never been used to describe perceived health perception in a SCI population before.

The result of a previous study assessing quality-of-life in individuals with SCI across six countries worldwide showed that quality-of-life differences between countries could not be accounted for on the basis of demographic and lesion-related characteristics. ${ }^{35}$

In a large cross-sectional survey, ${ }^{36}$ health status in the general population of six European countries was compared. The mean EQ-VAS score in the cross-sectional survey was higher as compared with our study cohort $(77.00 \pm 21$ vs $67 \pm 22) .{ }^{36}$ When compared to other disease populations such as, for example, Parkinson's disease (PD), the tetraplegia cohort in the present study scored relatively well. ${ }^{37-41}$ In the cited studies, the mean EQ-VAS score for the PD

Table 3 Intercorrelation matrix of different dimensions of participants' functioning and health

\begin{tabular}{|c|c|c|c|c|c|c|c|c|}
\hline & 1 & 2 & 3 & 4 & 5 & 6 & 7 & 8 \\
\hline 2. Activity ${ }^{a}$ & & 1.00 & $0.50 * *$ & $0.63^{* *}$ & -0.22 & -0.32 & -0.19 & 0.08 \\
\hline 4. EQ-VAS score $(N=54)$ & & & & 1.00 & -0.14 & -0.35 & 0.02 & 0.05 \\
\hline 5. Key pinch at 6 months $(N=24)$ & & & & & 1.00 & $0.94^{* *}$ & $0.53^{*}$ & $0.57^{*}$ \\
\hline 6. Key pinch at 12 months $(N=24)$ & & & & & & 1.00 & 0.46 & $0.58^{* *}$ \\
\hline
\end{tabular}

Abbreviation: $\mathrm{EQ}-\mathrm{VAS}=$ EuroQol Visual Analogue Scale.

aPart of the satisfaction questionnaire. ${ }^{*} P<0.05 ;{ }^{*} P<0.01$ 
populations ranged between 47.7 and 67.8. A well-known limitation of the measurement instrument VAS is the so-called end-of-scale bias, meaning that respondents are less likely to use the extreme ends of the scale for rating their health status. However, although simple in its quality-of-life questions, it is still considered to be a useful, direct method for assigning health-related quality-of-life (HRQoL) weightings. ${ }^{42}$ Since the aim of this study was to give an overall perspective on health-related quality of life, we used this generic instrument for assessing self-reported health. It also gives the possibility to compare results between both diseased and healthy populations.

Early activation is important following tetraplegia surgery, and exercises are carefully and gradually progressed into training of motor control, coordination and activities of daily living (ADL) ${ }^{43,44}$ Starting early active mobilization on the first postoperative day not only activates the transferred muscle but also prevents adhesions. According to the Swedish rehabilitation protocol, it is not until 3 months after surgery that strength training of transferred tendons is allowed. ${ }^{43}$ The results of the present study, however, indicate that strength training of restored function is not of critical importance for the purposes of functional long-term gains. The negative correlation between the category, general satisfaction and strength in the pinch grip at 12 months $(r:-0.43)$ support this statement even though the finding was considered implausible. Lack of significant correlation between grip strength and satisfaction with activity performance has been shown in a previous study. ${ }^{24}$ Therefore, continued emphasis should be placed on fine-tuning the motor control and coordination in restored functions, as well as making advancements in activity-based training in addition to providing strength training of the transferred muscle. Patients should therefore be encouraged to use their restored functions in daily activities as soon as allowed. ${ }^{43}$

Surgical reconstruction of grip functions not only restores the capacity to grasp objects but also improves the ability to release them, which impact on activities such as picking up objects, using a computer mouse and shaking hands. ${ }^{45}$ In order to identify different life satisfaction trajectories in the period between the start of active spinal cord injury (SCI), rehabilitation and 5 years after discharge, van Leeuven et al. ${ }^{46}$ conducted a multicenter prospective cohort study. The study showed that demographic, lesion, physical and social characteristics recorded at the start of rehabilitation cannot predict life satisfaction trajectories. The authors state that personal factors may be predictors of life satisfaction after SCI's, as shown in recent studies. ${ }^{47,48}$

Since the data in the Swedish satisfaction survey were collected using a cross-sectional design, there was no possibility of providing information on changes in perceived health. Also, it was not possible to include any objective measures since the study was conducted as a postal survey. Hence, it is unclear whether physical parameters of surgical success are preserved. Previous studies were aimed at investigating long-term results after reconstructive upper-limb surgery in tetraplegia and comparing these with the short-term results. In these studies, it was demonstrated that hand function improvements gained as a result of tendon transfers and tenodeses were, for the most part, maintained over time. ${ }^{17,49}$ It was also shown that diminished strength over time had no negative impact on the independence gained from the procedure. ${ }^{17,49}$

Despite the clear evidence for functional gains reported after tetraplegia upper-limb surgery, the intervention is highly underutilized. The low utilization of reconstructive upper-limb surgery is an important global issue..$^{50-52}$ One of the most common reasons for the low uptake of this type or surgical rehabilitation is the lack of knowledge of the value of this type of surgery. ${ }^{53}$ This lack of proven long-term effectiveness makes it difficult for individuals with spinal cord injury to obtain the guidance they need to help them in their decision-making process. Inadequate information leading to skepticism among therapists, rehabilitation physicians as well as patients is a reason suggested to account for this paradox. ${ }^{1}$ A previous study demonstrates that making the decision whether or not to have surgery is dependent upon a number of temporal issues such as stability of the home environment as well as caregiver support and hope. The authors conclude that in order to take into account the temporality of the issues that influence the individual's decision-making process, multiple offers of surgery are recommended throughout the individual's lifetime. ${ }^{50}$ In a qualitative study by Dunn et al., ${ }^{54}$ it wa/s shown that many influences on the decision about surgery had a temporal element, such as hope for the cure or recovery from SCI, inadequate physical or social supports while rehabilitating, life roles and goals and the avoidance of rehospitalization. Changes in prioritized activities, and the identification of tasks possible with surgery, are shown to be influential in the decision-making process. ${ }^{55}$ Another important barrier to the appropriate use of upper-limb reconstruction for individuals with tetraplegia is inadequate referral networks ${ }^{56}$ and the lack of a coordinated crossspecialty relationship. ${ }^{52}$ In order to improve care substantially for individuals with spinal cord injury, it is recommended that spinal cord treatment teams and hand surgeons collaborate with the aim of coordinating partnerships to enhance communication and ultimately lead to new findings and the necessary referrals. ${ }^{52}$

\section{CONCLUSION}

The gains achieved after tetraplegia surgery could be linked to the ICF constructs, body functions/structures and activity with 'handling objects' and 'maneuvering a wheelchair' as the most frequently reported functional gains. Perceived gains suggest possible implications on participation, personal and environmental factors. The overall health perception was relatively high and could be linked to the degree of satisfaction among participants. Muscle strength is not necessarily transferable to activity performance, highlighting the importance of addressing other factors rather than strength during postop rehabilitation and assessments.

\section{DATA ARCHIVING}

There were no data to deposit.

\section{CONFLICT OF INTEREST}

The authors declare no conflict of interest.

\section{ACKNOWLEDGEMENTS}

The authors affirm that the manuscript is an honest, accurate and transparent account of the study being reported; that no important aspects of the study have been omitted; and that any discrepancies from the study as planned (and, if relevant, registered) have been explained.

\section{AUTHOR CONTRIBUTIONS}

All authors contributed to the rationale and conceptualization of the study. LBK coordinated the study and contributed to the data collection and analyses. LBK, JW, CR and JF contributed to the interpretation of the results. All authors wrote the manuscript and approved its final version and had final responsibility for the decision to submit for publication. 
1 Fridén J, Gohritz A. Tetraplegia Management Update. J Hand Surg Am 2015; 40 2489-2500.

2 Dunn JA, Sinnott KA, Rothwell AG, Mohammed KD, Simcock JW. Tendon transfer surgery for people with tetraplegia: an overview. Arch Phys Med Rehabil 2016; 97. S75-S80.

3 Mulcahey M, Hutchinson D, Kozin S. Assessment of upper limb in tetraplegia: considerations in evaluation and outcomes research. J Rehabil Res Dev 2007; 44 91.

4 Sinnott KA, Dunn JA, Wangdell J, Johanson ME, Hall AS, Post MW. Measurement of outcomes of upper limb reconstructive surgery for tetraplegia. Arch Phys Med Rehabil 2016; 97: S169-S181.

5 Donabedian A. The Definition of Quality and Approaches to its Management, Vol 1: Explorations in Quality Assessment and Monitoring. Health Administration Press: Ann Arbor, MI, USA. 1978.

6 Organization WH. International Classification of Functioning, Disability and Health: ICF. World Health Organization. 2001.

7 Bryden A, Sinnott A, Mulcahey M. Innovative strategies for improving upper extremity function in tetraplegia and considerations in measuring functional outcomes. Top Spinal Cord Inj Rehabil 2005; 10: 75-93.

8 Sinnott K, Dunn J, Rothwell A. Use of the ICF conceptual framework to interpret hand function outcomes following tendon transfer surgery for tetraplegia. Spinal Cord 2004; 42: 396-400.

9 Kirchberger I, Biering-Sørensen F, Charlifue S, Baumberger M, Campbell R, Kovindha A et al. Identification of the most common problems in functioning of individuals with spinal cord injury using the International Classification of Functioning, Disability and Health. Spinal Cord 2010; 48: 221-229.

10 Cieza A, Kirchberger I, Biering-Sørensen F, Baumberger M, Charlifue S, Post M et al. ICF Core Sets for individuals with spinal cord injury in the long-term context. Spinal Cord 2010; 48: 305-312.

11 Kirchberger I, Cieza A, Biering-Sørensen F, Baumberger M, Charlifue S, Post M et al. ICF Core Sets for individuals with spinal cord injury in the early post-acute context. Spinal Cord 2010; 48: 297-304.

12 Stucki G. ICF linking rules: an update based on lessons learned. J Rehabil Med 2005 37: $212-218$.

13 Wangdell J, Carlsson G, Friden J. From regained function to daily use: experiences of surgical reconstruction of grip in people with tetraplegia. Disabil Rehabil 2014; 36: 678-684.

14 Wangdell J, Friden J. Satisfaction and performance in patient selected goals after grip reconstruction in tetraplegia. J Hand Surg (Eur Vol) 2010; 35: 563-568.

15 Mohammed KD, Rothwell AG, Sinclair SW, Willems S, Bean AR. Upper-limb surgery for tetraplegia. Bone Joint J 1992; 74: 873-879.

16 Rothwell AG, Sinnott KA, Mohammed KD, Dunn JA, Sinclair SW. Upper limb surgery for tetraplegia: a 10-year re-review of hand function. J Hand Surg Am 2003; 28: 489-497.

17 Dunn JA, Rothwell AG, Mohammed KD, Sinnott KA. The effects of aging on upper limb tendon transfers in patients with tetraplegia. J Hand Surg Am 2014; 39: 317-323.

18 Bunketorp Käll L, Reinholdt, Fridén J, Wangdell J. Long-term satisfaction with upper limb reconstructive surgery in tetraplegic individuals: the development and reliability of a Swedish self-reported satisfaction questionnaire. 21 February 2017 doi:10.1038/sc.2017.12.

19 Wuolle KS, Bryden AM, Peckham PH, Murray PK, Keith M. Satisfaction with upperextremity surgery in individuals with tetraplegia 1, 2. Arch Phys Med Rehabil 2003; 84 1145-1149.

20 Jaspers Focks-Feenstra JH, Snoek GJ, Bongers-Janssen HM, Nene AV. Long-term patient satisfaction after reconstructive upper extremity surgery to improve arm-hand function in tetraplegia. Spinal Cord 2011; 49: 903-908.

21 Gregersen H, Lybaek M, Lauge Johannesen I, Leicht P, Nissen UV, Biering-Sorensen F. Satisfaction with upper extremity surgery in individuals with tetraplegia. J Spinal Cord Med 2015; 38: 161-169.

22 Moberg E, McDowell CL, House JH. Third international conference on surgical rehabilitation of the upper limb in tetraplegia (quadriplegia). J Hand Surg Am 1989; 14: 1064-1066.

23 Michener SKW, Olson AL, Humphrey BA, Reed JE, Stepp DR, Sutton AM et al. Relationship among grip strength, functional outcomes, and work performance following hand trauma. Work 2001; 16: 209-217.

24 Wangdell J, Fridén J. Performance of prioritized activities is not correlated with functional factors after grip reconstruction in tetraplegia. J Rehabil Med 2011; 43 626-632.

25 Herdman M, Gudex C, Lloyd A, Janssen M, Kind P, Parkin D et al. Development and preliminary testing of the new five-level version of EQ-5D (EQ-5D-5L). Qual Life Res 2011; 20: 1727-1736.

26 Sisto SA, Dyson-Hudson T. Dynamometry testing in spinal cord injury. J Rehabil Res Dev 2007; 44: 123-136.

27 Vanden Berghe A, Van Laere M, Hellings S, Vercauteren M. Reconstruction of the upper extremity in tetraplegia: functional assessment, surgical procedures and rehabilitation. Paraplegia 1991; 29: 103-112.

28 Cicchetti DV. Guidelines, criteria, and rules of thumb for evaluating normed and standardized assessment instruments in psychology. Psychol Assess 1994; 6: 284.
29 Sinnott A, Brander P, Siegert R, Rothwell A, De Jong G. Life impacts following reconstructive hand surgery for tetraplegia. Top Spinal Cord Inj Rehabil 2009; 15 90-97.

30 Laffont I, Hoffmann G, Dizien O, Revol M, Roby-Brami A. How do C6/C7 tetraplegic patients grasp balls of different sizes and weights? Impact of surgical musculo-tendinous transfers. Spinal Cord 2007; 45: 502-512.

31 Noreau L, Fougeyrollas P, Post M, Asano M. Participation after spinal cord injury: the evolution of conceptualization and measurement. J Neurol Phys Ther 2005; 29: 147-156.

32 Magasi SR, Heinemann AW, Whiteneck GG. Participation following traumatic spinal cord injury: an evidence-based review for research. J Spinal Cord Med 2008; 31: $145-156$.

33 Whiteneck G, Dijkers MP. Difficult to measure constructs: conceptual and methodological issues concerning participation and environmental factors. Arch Phys Med Rehabil 2009; 90: S22-S35.

34 Kreuter M, Sullivan M, Dahllöf A, Siösteen A. Partner relationships, functioning, mood and global quality of life in persons with spinal cord injury and traumatic brain injury. Spinal Cord 1998; 36: 252-261.

35 Geyh S, Ballert C, Sinnott A, Charlifue S, Catz A, Greve JDA et al. Quality of life after spinal cord injury: a comparison across six countries. Spinal Cord 2013; 51: 322-326.

36 König H-H, Bernert S, Angermeyer MC, Matschinger H, Martinez M, Vilagut G et al. Comparison of population health status in six european countries: results of a representative survey using the EQ-5D questionnaire. Med Care 2009; 47: 255-261.

37 Reuther M, Spottke E, Klotsche J, Riedel O, Peter H, Berger K et al. Assessing health-related quality of life in patients with Parkinson's disease in a prospective longitudinal study. Parkinsonism Relat Disord 2007; 13: 108-114.

38 Schrag A, Jahanshahi M, Quinn N. How does Parkinson's disease affect quality of life? A comparison with quality of life in the general population. Mov Disord 2000; 15: 1112-1118.

39 Visser M, van Rooden SM, Verbaan D, Marinus J, Stiggelbout AM, van Hilten JJ. A comprehensive model of health-related quality of life in Parkinson's disease. $J$ Neurol 2008; 255: 1580-1587.

40 Winter Y, von Campenhausen S, Gasser J, Seppi K, Reese J-P, Pfeiffer K-P et al. Social and clinical determinants of quality of life in Parkinson's disease in Austria: a cohort study. J Neurol 2010; 257: 638-645.

41 Winter Y, von Campenhausen S, Popov G, Reese JP, Balzer-Geldsetzer M, Kukshina A et al. Social and clinical determinants of quality of life in Parkinson's disease in a Russian cohort study. Parkinsonism Relat Disord 2010; 16: 243-248.

42 Krabbe P, Weijnen T. Guidelines for analysing and reporting EQ-5D outcomes. In: Brooks R, Rabin R, De Charro F (eds), The Measurement and Valuation of Health Status Using EQ-5D: A European Perspective (evidence from the EuroQol BIOMED Reasearch Programme). Kluwer Academic Publishers: Dordrecht, Netherlands, 2003; pp 7-19.

43 Wangdell J, Bunketorp-Käll L, Koch-Borner S, Fridén J. Early active rehabilitation after grip reconstructive surgery in tetraplegia. Arch Phys Med Rehabil 2016; 97 S117-S125.

44 Johanson ME. Rehabilitation After Surgical Reconstruction to Restore Function to the Upper Limb in Tetraplegia: A Changing Landscape. Arch Phys Med Rehabil 2016; 97 S71-S74.

45 Reinholdt C, Fridén J. Outcomes of single-stage grip-release reconstruction in tetraplegia. J Hand Surg Am 2013; 38: 1137-1144.

46 van Leeuwen CM, Post MW, Hoekstra T, van der Woude LH, de Groot S, Snoek GJ et al. Trajectories in the course of life satisfaction after spinal cord injury: identification and predictors. Arch Phys Med Rehabil 2011; 92: 207-213.

47 Mortenson W, Noreau L, Miller W. The relationship between and predictors of quality of life after spinal cord injury at 3 and 15 months after discharge. Spinal Cord 2010; 48: 73-79.

48 Kortte KB, Gilbert M, Gorman P, Wegener ST. Positive psychological variables in the prediction of life satisfaction after spinal cord injury. Rehabil Psychol 2010; 55: 40.

49 Vastamäki M. Short-term versus long-term comparative results after reconstructive upper-limb surgery in tetraplegic patients. J Hand Surg Am 2006; 31: 1490-1494.

50 Dunn J, Hay-Smith E, Whitehead L, Keeling S. Issues influencing the decision to have upper limb surgery for people with tetraplegia. Spinal Cord 2012; 50: 844-847.

51 Squitieri L, Chung KC. Current utilization of reconstructive upper limb surgery in tetraplegia. Hand Clin 2008; 24: 169-173.

52 Curtin CM, Hayward RA, Kim HM, Gater DR, Chung KC. Physician perceptions of upper extremity reconstruction for the person with tetraplegia. J Hand Surg Am 2005; 30: 87-93.

53 Hamou C, Shah NR, DiPonio L, Curtin CM. Pinch and elbow extension restoration in people with tetraplegia: a systematic review of the literature. J Hand Surg Am 2009; 34: 692-699.

54 Dunn JA, Hay-Smith EJC, Whitehead LC, Keeling S. Liminality and decision making for upper limb surgery in tetraplegia: a grounded theory. Disabil Rehabil 2013; 35: 1293-1301.

55 Dunn JA, Hay-Smith EJ, Keeling S, Sinnott KA. Decision-making about upper limb tendon transfer surgery by people with tetraplegia for more than 10 years. Arch Phys Med Rehabil 2016; 97: S88-S96.

56 Curtin CM, Gater DR, Chung KC. Upper extremity reconstruction in the tetraplegic population, a national epidemiologic study. J Hand Surg Am 2005; 30: 94-99. 